\title{
Trained and Ready, but Not Serving?-Family Physicians' Role in Reproductive Health Care
}

\author{
Meenadchi Chelvakumar, MD, MPH and Jonathan G. Shaw, MD, MS
}

(J Am Board Fam Med 2020;33:182-185.)

Family physicians (FPs) are a crucial and integral part of the women's health primary care workforce. The majority of outpatient healthcare sought by women of reproductive age is to obstetrician-gynecologists or FPs, ${ }^{1,2}$ with FPs providing roughly $1 / 3$ of all outpatient care sought by women over age $30 .{ }^{1}$ FPs are especially important in underserved settings, such as rural clinics and community health centers, where they may be the only source of medical care for patients facing salient socioeconomic and racial disparities. ${ }^{3}$

Given the numerous barriers women of reproductive age encounter in being able to access gender specific services, ${ }^{4,5}$ it is especially important that FPs are able meet the holistic needs of the women for whom they care. In addition, inadequate access to contraception, prenatal care, and basic preventive and sexual health services can have farreaching effects on women and their families. ${ }^{6,7}$

In this current issue of the $\mathcal{F} A B F M$, the policy brief by Coffman et $\mathrm{al}^{8}$ provides an important snapshot of recently graduated FP's preparation for and practice of women's health services. Using cross-sectional survey data of physicians 3 years out of training, the authors give reason for both optimism and concern. Although the majority of recent FP graduates report having received adequate training in long-acting reversible contraception (LARC) placement, endometrial biopsy, and colposcopy, as few as one-fourth of those graduates use these skills in practice. The

From the Division of Primary Care \& Population Health, Department of Medicine, Stanford University (MC); Department of Obstetrics and Gynecology, Stanford University (JGS).

Corresponding author: Meenadchi Chelvakumar, MD, MPH, Stanford University, Palo Alto, CA 94305 (E-mail: meenac@stanford.edu).

\section{See Related Article on Page 186.}

largest absolute discrepancy between training and independent practice for recent graduates is in maternity care, where $90 \%$ report adequate training but only $26 \%$ report currently practicing. For abortion care, the deficit starts in training, with less than 20\% of recent graduates reporting training in surgical abortion or incomplete miscarriage management (ie, uterine aspiration) and less than 5\% reporting offering these services-a finding that is concerning considering that abortion is a predominantly outpatient procedure that 1 in 4 women report needing in their lifetime. ${ }^{9,10}$

\section{Why the Gap?}

The reasons that new FPs do not provide women's health services despite having adequate training are multifactorial, including individual choices and external factors. For example, lifestyle preferences come into play when deciding whether to provide obstetric care. ${ }^{11-13}$

Coffman et $\mathrm{al}^{8}$ observe moderate differences in practice patterns between male and female FPs (45\% vs $65 \%$ providing some reproductive health service), which may relate to provider or patient preferences. ${ }^{14}$ After personal preferences, decisions on their scope of practice may be affected by the needs of one's patient population. We fear, however, that the drop-off from training to subsequent practice is also affected by system and policy-level factors, clinic and hospital logistic constraints, liability concerns, as well as reimbursement issues.

\section{Why Does it Matter?}

Equally important as understanding the reasons that new FPs are not applying the full breadth of their training in women's health is understanding how this interacts with women's access to necessary 
care. Although the most sanguine interpretation is that the demands for women's health are being met elsewhere, the large gap likely reflects an unmet need, especially in rural and underserved communities that most heavily rely on FPs. ${ }^{15,16}$

One area where the gaps for provision are indisputable is abortion and miscarriage management. Large regions of the nation do not have access to these services, ${ }^{17}$ with women residing in 27 major cities having to travel more than 100 miles to obtain an abortion and $90 \%$ of US counties lacking an abortion provider. ${ }^{18}$ For this politically infused, yet ubiquitous, component of women's office-based care, FP training and practice are certainly affected by individual preferences and ethical beliefs, and we expect that not all FPs would be comfortable providing this service. We fear, however, that the extremely low proportion of FPs trained in abortion care might more reflect decreased training opportunities as well as cumbersome legal and logistic barriers, rather than the needs of the communities that rely on our graduating FPs for comprehensive medical care. FPs see women across their reproductive life span, including in the pediatric age groups, and are often the first medical point of contact when a pregnancy diagnosis is made. FPs are, thus, well positioned to be timely providers of abortion services. Increases over the past 2 decades in legislation that restricts physicians' ability to provide these medically necessary services are already leading to a dwindling number of abortion providers ${ }^{17}$ that, in turn, can make it difficult for trainees to gain such skills. These legislative restrictions largely have no basis in medical guidelines and are explicit efforts to restrict abortion access, largely on ideological grounds. ${ }^{19}$ Furthermore, recent graduates who report adequate training in abortion provision cite a myriad of individual and systemic barriers to providing such care, such as needing to prioritize competing clinical interests, lack of time, and hospi$\mathrm{tal} /$ clinic restrictions in their ability to perform these procedures. $^{20}$

\section{Reasons for Optimism and Ways Forward}

Still, we remain optimistic, buoyed by recognition that FP careers are not static, and as a specialty, FPs evolve their clinical practices to keep up with the changing needs of populations and evidence-based practices. In the authors' own anecdotal experience working across academic, Veterans Health Administration (VA), and community health clinic settings, our degree of provision of reproductive services has varied and adapted at each career transition-both in response to factors including whether patients had other access to reproductive health services or were relying more exclusively on us for such services. With this in mind, there are several promising approaches to ensure our specialty supports reproductive health and it remains part of the key services offered to our patients.

One exemplar of such an effort is Reproductive Health Education in Family Medicine (RHEDI), ${ }^{21}$ which provides funding to residency programs to establish a rotation in family planning-including contraception and abortion training. Studies have shown that such rotations not only significantly enhance FP skills in abortion provision but also increases their readiness to provide other related services, such as LARC and obstetric ultrasounds. ${ }^{20}$ Once in practice, RHEDI-trained FPs provide these services at higher rates than their counterparts who did not receive comprehensive reproductive health training. ${ }^{21}$

Providing career-specific tracks during residency has additionally been raised as a potential strategy to help FPs develop and retain their desired scope of practice in a way that best fits the communities they will be serving. A recent study looking at the benefits of this type of longitudinal tracking within residency programs found that residents participating in such training were most likely to practice a wider scope of family medicine that included full spectrum women's health services. ${ }^{22}$

Recognizing that practice trajectories after training are not static, support after training may be particularly helpful. For example, the Reproductive Health Access Project (www.reproductiveaccess. org) works directly with primary care providers to provide resources and training in contraception, abortion, and miscarriage management after formal residency training. Such postresidency support can also help FPs navigate the systemic and logistic barriers that might prevent adequately trained doctors from being able to fully provide these services, which might be particularly necessary for those in independent and rural practice.

Another health system-wide example that might serve as a model for postresidency physician training is the approach the VA has taken to adapt their primary care workforce to the increases in the number of women Veterans into the VA system following 
the conflicts in the Middle East. Implementation of Women's Health Mini-Residencies ${ }^{23,24}$ were launched as a way to proactively train clinicians to provide evidence-based gender-specific care to their patients. These are 3-day programs where clinicians receive comprehensive didactics, lectures, and hands-on instructions in important primary care women's and reproductive health issues as well as health topics specific to Veterans. Evaluation confirms the success of this approach in increasing the efficacy of primary care providers' provision of gender-specific care and increased satisfaction of care among women Veterans. $^{25}$

FPs are the only medical providers trained to deliver care to all individuals regardless of age or sex, an important skillset for our patients who might otherwise have to switch primary care providers at every age or reproductive milestone. Individual FPs are well trained to meet the needs of those trying to receive basic reproductive health services $^{26}$ in what is an increasingly politicized aspect of health care. More understanding of what is keeping this prepared workforce from serving those needs is urgently needed. Future research must focus at the community/geographic level and the practice type level, as the roles FPs play are undoubtedly different for rural and underserved communities and in multispecialty versus individual practice settings. Once we understand more about the gaps in reproductive health service needs, we can leverage the existing strong training of FPs to best meet the needs of the populations we serve.

To see this article online, please go to: http://jabfm.org/content/ 33/2/182.full.

\section{References}

1. Hudson Scholle S, Chang JC, Harman J, McNeil M. Trends in women's health services by type of physician seen: data from the 1985 and 1997-98 NAMCS. Womens Health Issues 2002;12:165-77.

2. Petterson SM, Bazemore AW, Phillips RL, Rayburn WF. Trends in office-based care for reproductive-aged women according to physician specialty: a ten-year study. J Womens Health (Larchmt) 2014;23:1021-6.

3. Fryer GE, Green LA, Dovey SM, Phillips RI, Jr. The United States relies on family physicians unlike any other specialty. Am Fam Physician 2001;63: 1669.

4. Salganicoff A, Ranji U, Beamesderfer A, Kurani N. Women and health care in the early years of the ACA: key findings from the 2013 Kaiser Women's
Health Survey. Menlo Park (CA): The Henry J. Kaiser Family Foundation; 2014.

5. Ogburn T, Voss C, Espey E. Barriers to women's health: why is it so hard for women to stay healthy? Obstet Gynecol Clin North Am 2009;36:737-52.

6. Trussell J, Henry N, Hassan F, Prezioso A, Law A, Filonenko A. Burden of unintended pregnancy in the United States: potential savings with increased use of long-acting reversible contraception. Contraception 2013;87:154-61.

7. Sonfield A, Gold RB. Medicaid family planning expansions: lessons learned and implications for the future. New York, NY: Guttmacher Institute; 2011.

8. Coffman M, Wilkinson E, Jabbarpour Y. Despite adequate training, only half of family physicians provide women's healthcare services. J Am Board Fam Med 2020;33:186-188.

9. Jones RK, Jerman J. Population group abortion rates and lifetime incidence of abortion: United States, 2008-2014. Am J Public Health 2017;107:1904-9.

10. National Academies of Sciences, Engineering, and Medicine. The safety and quality of abortion care in the United States. Washington DC: National Academies Press; 2018.

11. Greenberg DM, Hochheiser LI. Family practice residents' decision making regarding future practice of obstetrics. J Am Board Fam Pract 1994;7:25-30.

12. Roberts RG, Bobula JA, Wolkomir MS. Why family physicians deliver babies. J Fam Pract 1998;46:34-40.

13. Ruderman J, Holzapfel SG, Carroll JC, Cummings S. Obstetrics anyone? How family medicine residents' interests changed. Can Fam Physician 1999;45:63840, 643-7.

14. Schmittdiel J, Selby JV, Grumbach K, Quesenberry $\mathrm{CP}, \mathrm{Jr}$. Women's provider preferences for basic gynecology care in a large health maintenance organization. J Womens Health Gend Based Med 1999;6:825-33.

15. Kozhimannil KB, Casey MM, Hung P, Han X, Prasad S, Moscovice IS. The rural obstetric workforce in US hospitals: challenges and opportunities. J Rural Health 2015;31:365-72.

16. Hung P, Kozhimannil KB, Casey MM, Moscovice IS. Why are obstetric units in rural hospitals closing their doors? Health Serv Res 2016;51:1546-60.

17. Jones RK, Jerman J. Abortion incidence and service availability in the United States, 2014. Perspect Sex Repro H 2017;49:17-27.

18. Cartwright AF, Karunaratne M, Barr-Walker J, Johns NE, Upadhyay UD. Identifying national availability of abortion care and distance from major US cities: systematic online search. J Med Internet Res 2018;20:e186.

19. Gold RB, Nash E. Flouting the facts: state abortion restrictions flying in the face of science. Guttmacher Policy Review 2017;20:53-9. 
20. Goodman S, Shih G, Hawkins M, et al. A longterm evaluation of a required rotation with opt-out provisions for family medicine residents. Fam Med 2013;45:180-6.

21. Summit AK, Gold M. The effects of abortion training on family medicine residents' clinical experience. Fam Med 2017;49:22-7.

22. Young RA, Casey D, Singer D, Waller E, Carney PA. Early career outcomes of family medicine residency graduates exposed to innovative flexible longitudinal tracks. Fam Med 2017;49:353-60.

23. Mengeling MA, Sadler AG, Torner J, Booth BM. Evolving comprehensive VA women's health care: patient characteristics, needs, and preferences. Womens Health Issues 2011;21:S120-S129.

24. Seelig MD, Yano EM, Bean-Mayberry B, Lanto $\mathrm{AB}$, Washington DL. Availability of gynecologic services in the Department of Veterans Affairs. Women's Health Issues 2008;18:167-73.

25. Bastian LA, Trentalange M, Murphy TE, et al. Association between women veterans' experiences with VA outpatient health care and designation as a women's health provider in primary care clinics. Womens Health Issues 2014;24:605-12.

26. Weidner AKH, Chen FM. Changes in preparation and practice patterns among new family physicians. Ann Fam Med 2019; 17:46-8. 